\section{Irrigation Strategies for Greenhouse Tomato Production on Rockwool}

\author{
Uttam K. Saha, Athanasios P. Papadopoulos ${ }^{1}$, and Xiuming Hao \\ Greenhouse and Processing Crops Research Centre, Agriculture and Agri- \\ Food Canada, 2585 County Road 20, Harrow, Ontario, N0R 1G0 Canada
}

\author{
Shalin Khosla \\ Ontario Ministry of Agriculture and Food Greenhouse and Processing, \\ Crops Research Centre, Agriculture and Agri-Food Canada, 2585 County \\ Road 20, Harrow, Ontario, NOR 1G0 Canada
}

Additional index words. electrical conductivity, irrigation, Lycopersicum esculentum, rockwool, water content, yield

\begin{abstract}
To address the concern that irrigation provides sufficient water to match the crop needs, while not impeding oxygen availability to the roots, we conducted an experiment to develop suitable irrigation schedule(s) for greenhouse tomato (Lycopersicon esculentum Mill.) on rockwool. The experimental treatments incorporated the electrical conductivity (EC) of the nutrient solution in the rockwool slab (slab-EC) along with the water content (WC) in the rockwool slab (slab-WC) as the irrigation decisionmaking variables. They were: slab-WC $\leq 70 \%$ or slab-EC $\geq 1.4 \times$ normal or more (T1), slab-WC $\leq 70 \%$ or slab-EC $\geq 1.7 \times$ normal or more $(\mathrm{T} 2)$, slab-WC $\leq 80 \%$ or slab-EC $\geq$ $1.4 \times$ normal or more (T3), slab-WC $\leq 80 \%$ or slab-EC $\geq 1.7 \times$ normal or more (T4), and the combined weight loss (WL) $700 \mathrm{~g}$ or more (T5) and WL $500 \mathrm{~g}$ or more (T6), in which "normal" means the feed solution EC as recommended in the seasonal fertigation schedule for a spring-summer tomato crop. The data on early-season marketable yield, total seasonal marketable yield, and fruit grades indicated the superiority of treatments T1, T2, and T6 over T3, T4, and T5. Better root growth was observed with T1, T2, and T6 and this was also associated with minimized nutrient solution leaching; furthermore, these plants had an abundance of coarse and fine roots, higher photosynthesis and transpiration, higher marketable yield, and a higher water use efficiency. Our results thus established that irrigation based on either a slab water content $70 \%$ or less or a $500-\mathrm{g}$ weight loss is the best strategy for rockwool-grown greenhouse tomatoes in the springsummer season. A variation in slab-EC between 1.4 and $1.7 \times$ normal, at a slab-WC of $\mathbf{7 0 \%}$ or less, would have no significant effect on root growth, water use, marketable yield, or fruit grades.
\end{abstract}

Soilless crop cultivation has become a preferred practice in the greenhouse industry (Van Os and Benoit, 1999); the most widely used soilless system is growing crops on rockwool (Sonneveld, 1991). In comparison with the common soil-based production system, the soilless methods have increased the productivity significantly. However, further yield increases have been difficult as a result of several limiting factors such as unsatisfactory spatial root development, rapid root collapse, and occasional disease incidence. Improved water management could alleviate these problems, to some extent, because it would improve waterair distribution in the growing medium, thereby improving plant health and productivity. Irrigation in soilless cultivation is indeed

\footnotetext{
Received for publication 20 Sept. 2007. Accepted for publication 19 Dec. 2007.

This research was funded, in part, by the Ontario Greenhouse Vegetable Growers.

The skillful technical support of Ms. Janet Blackburn and Ms. Celeste Breault is gratefully acknowledged.

${ }^{1}$ To whom reprint requests should be addressed; e-mail papadopoulost@agr.gc.ca
}

fertigation, in which plants are supplied with complete nutrient solution rather than water. As explained by Warren and Bilderback (2004), irrigation scheduling is the process of determining how much water (or nutrient solution) to apply (i.e., irrigation volume) and timing (when to apply). The goal of irrigation scheduling is to control the water status of the crop for a targeted level of plant performance. The targeted performance level is largely situational; it could be optimizing irrigation input for maximizing yield or economic return or increasing water use efficiency.

The root zone oxygen level has immediate effects on root formation (Gislerod, 1983; Soffer and Burger, 1988) and growth (Soffer et al., 1991), water and nutrient uptake, and many other metabolic activities (Morard et al., 2000). Hence, it is one of the principal determinants of water and nutrient use efficiency as well as plant growth and yield. Although the soilless growing media including rockwool are considered well-aerated in comparison with soil, events of oxygen deficiency are common (Allaire et al., 1996). This is because greenhouse crops grown on rockwool (or other soilless media) generally have higher growth rate and hence increased rate of root respiration (Raviv et al., 2004), thereby demanding more oxygen. Furthermore, in satisfying the increased water demand of a rapidly growing crop, it becomes harder to have enough air in the medium, because the water and air are nearly mutually exclusive in the pore spaces of the medium. Thus, ensuring an adequate oxygen supply to the roots is of paramount importance, and it is a difficult task even when the greenhouse crops are grown on rockwool or other carefully chosen well-aerated media (Soffer et al., 1991). The key consideration to ensure an adequate root zone oxygen level is to maintain a proper balance between water and air distribution in the slab by regulating the water content through supplying the right amount of water (or nutrient solution) at the right time, i.e., the development of an appropriate irrigation/fertigation control scheme for a particular crop under certain conditions. If developed and adopted, such an appropriate irrigation/fertigation control scheme would eventually result in further yield increases.

Intensive greenhouse crop production in rockwool and other soilless media usually involves sufficient water discharge aimed at preventing localized water shortage or salinity buildup in some slabs. The required leaching factor (i.e., the ratio of leached water to irrigation water) under these conditions may be $25 \%$ to $50 \%$ depending on the electrical conductivity (EC) of the feed solution and climatic conditions (Kläring, 2001; Van Os, 1995). One tomato plant is estimated to require $250 \mathrm{~L}$ of water during the growing season (Uronen, 1995). If the plant density is 2.5 plants $/ \mathrm{m}^{2}$, the water requirement is 625 $\mathrm{L} \cdot \mathrm{m}^{2}$. Considering the required leaching factor, the amount of water applied in practice is 781 to $938 \mathrm{~L} \cdot \mathrm{m}^{2}$ of growing area. Because greenhouse crop production is concentrated in certain areas, the discharge of drained water carrying unused nutrients from greenhouses is of some environmental concern (Santamaria et al., 2003). As an example, typically, up to $50 \%$ of the applied nitrogen is leached out of the medium in the form of nitrates (McAvoy, 1994). This causes a common nitrate concentration in the drained water in the range of 600 to $900 \mathrm{ppm}$ (McAvoy, 1994). High-nitrate water is unacceptable for human consumption. Soilless growing systems are considered potential contributors of nitrates to both under- and above-groundwater reservoirs in many horticulturally intensive countries (Van Os, 1995). Supplying fertigation to a crop at the correct time and in the correct amount will reduce the discharge of nutrients to the environment and will improve water management

Substantial research effort has already been devoted to establishing optimum schedules in drip-irrigated greenhouse crops (Bar-Tal et al., 2001; Jovicich et al., 2003; Papadopoulos and Tan, 1991). These studies often compared varying durations or frequencies of irrigation, on the basis of preset time intervals, in which the supply of water to the growing media was not fully matched with the amount of water used by the crop. We need 
to develop irrigation strategies that would optimize water and oxygen supply to the roots, which would ensure better root growth and function thereby ensuring better plant growth, increased yield, and improved quality. The physical properties of rockwool determine the critical water contents that ensure simultaneous optimal air and water supply in the root zone. Ideally, irrigation should then compensate for any amount of water that evaporated from the medium and transpired by the plants. Thus, irrigation control strategies based on the slab water content or on the extent of water lost from the slab (determined by balances) seemed to be promising.

The overall objective of this research was to study the effects of advanced irrigation control strategies on root growth, water use efficiency, yield and fruit quality of tomato, thereby developing proper irrigation schedules for rockwool-grown tomato crops.

\section{Materials and Methods}

\section{General crop husbandry and experimental design}

Research was conducted in the greenhouse facilities of Greenhouse and Processing Crops Research Centre of Agriculture and Agri-Food Canada, Harrow (lat. $42^{\circ} 16^{\prime} \mathrm{N}$, long. $82^{\circ} 58^{\prime} \mathrm{W}$ ), Ontario, Canada. A replicated experiment was conducted in the spring-summer season of 2005 to study the effects of various irrigation strategies on yield and water use of beefsteak type greenhouse tomato (Lycopersicum esculentum L.) on rockwool. Seeds (cv. Rapsodie; Rogers ${ }^{\circledR}$; Syngenta Seeds, Boise, ID) were sown in 3.8 $\mathrm{cm} \times 3.6 \mathrm{~cm} \times 4.0-\mathrm{cm}$ rockwool cubes on 14 Dec. 2004. After germination, when the cotyledons became fully unfolded, seedlings were transplanted into $7.62 \mathrm{~cm} \times 7.62 \mathrm{~cm} \times 7.6 \mathrm{~cm}$ rockwool blocks; there was one plant per seedling block. Transplants were raised on benches at a density of 12 plants $/ \mathrm{m}^{2}$ until their final planting in the greenhouse (14 Jan. 2005). All the rockwool growing media used in this study were FIBRgro ${ }^{\mathrm{TM}}$ Horticultural Products (Fibrex Insulations, Sarnia, Ontario, Canada). During the transplant rearing phase, the heating temperature was set at $18{ }^{\circ} \mathrm{C}$, whereas the ventilation/cooling set point was at $20{ }^{\circ} \mathrm{C}$. Day/night air humidity was set at $60 \% / 55 \%$. Carbon dioxide concentration was maintained at $1000 \mathrm{ppm}$ with liquid carbon dioxide when the light intensity was greater than $75 \mathrm{~W} \cdot \mathrm{m}^{-2}$ and the greenhouse was not ventilated. Supplemental lighting was provided for the period $1 \mathrm{~h}$-before-dawn to $1 \mathrm{~h}$ after-dusk when the ambient light was less than $500 \mathrm{~W} \cdot \mathrm{m}^{-2}$ with high-pressure sodium lamps $\left(190 \mathrm{~W} \cdot \mathrm{m}^{-2}\right.$ as installed capacity; 50 $\mu \mathrm{mol} \cdot \mathrm{m}^{-2} \cdot \mathrm{s}^{-1}$ photosynthetically active radiation). Final planting in the greenhouse was on $100 \mathrm{~cm} \times 15 \mathrm{~cm} \times 7.5-\mathrm{cm}$ rockwool slabs at a density of 2.5 plants $/ \mathrm{m}^{2}$. Plants were twisted around separate strings extended by overhead crop wires. Furthermore, plants were trained to a single stem and allowed to grow indeterminately by lowering regularly as and when their tips were about to reach the overhead wires (once/twice a week). Older and dead leaves were pruned once weekly as needed. Fruit was pruned regularly to four or five fruits per cluster.

Plants were fertigated using a Harrow Fertigation Manager (Papadopoulos, 1991; Papadopoulos and Liburdi, 1989) with nutrient solutions of varying composition according to climatic conditions and the age of the plants following standard commercial practices (Papadopoulos, 1998). The volume, $\mathrm{pH}$, and $\mathrm{EC}$ of feeding nutrient solutions received by the plants (through drippers delivering $2 \mathrm{~L} \cdot \mathrm{h}^{-1}$ ) were monitored regularly (five times weekly) by keeping an extra dripper in a 4-L collection beaker for each treatment. The same observations were also made daily on the leached-out solution or extracted samples from the growth media. Fine adjustments of the feed formula on the basis of the measured values of $\mathrm{EC}$ and $\mathrm{pH}$ (of both feeding nutrient and extracted solution) and the leach fraction were made but were very rarely required.

The heating temperature in the greenhouse was set at $19{ }^{\circ} \mathrm{C}$ day/ $18{ }^{\circ} \mathrm{C}$ night, whereas the ventilation/cooling set point was from 23 to $26{ }^{\circ} \mathrm{C}$ and varied according to the growth stage of the plants. The temperature inside the greenhouse ranged from 19.4 to $29.1{ }^{\circ} \mathrm{C}$. Day/night relative humidity $(\mathrm{RH})$ was set at $70 \% / 65 \%$, but it ranged from $51.8 \%$ to $96.8 \%$. Carbon dioxide concentration in the greenhouse was maintained at $1000 \mathrm{ppm}$ with liquid carbon dioxide when the light intensity was greater than $75 \mathrm{~W} \cdot \mathrm{m}^{-2}$ and the greenhouse was not ventilated. A computer was used to control heating, ventilation, carbon dioxide enrichment, humidity, and light (during transplant rearing) and to log environmental conditions.

There were six different irrigation treatments arranged in a randomized complete block design with eight replications. The eight blocks were placed in four rows, two blocks in a row. Each rockwool slab (i.e., a plot) supporting four plants formed an experimental unit. There were rows of sufficient number of guard plots surrounding the eight treatment blocks. In addition, there were inrow guard plants for adequate separation of the two blocks in a row.

The six irrigation treatments were: $\mathrm{T} 1$, slab-water content (slab-WC) $\leq 70 \%$ or slab$\mathrm{EC} \geq 1.4 \times$ normal or more; T2, slab-WC $\leq$ $70 \%$ or slab-EC $\geq 1.7 \times$ normal or more; T3, slab-WC $\leq 80 \%$ or slab-EC $\geq 1.4 \times$ normal or more; $\mathrm{T} 4$, slab-WC $\leq 80 \%$ or slab-EC $\geq$ $1.7 \times$ normal or more; T5, combined plant and growing medium weight loss (WL) $700 \mathrm{~g}$ or more; and. T6, WL $500 \mathrm{~g}$ or more, in which "normal" stands for normal feed nutrient solution EC for a spring-summer tomato crop as practiced commercially (Papadopoulos, 1998). Online electronic Grodan ${ }^{\circledR}$ water content meters (GRODAN BV, Model: WCM-A; Industrieweg 15, 6040 KD ROERMOND, The Netherlands) monitored continuously slab-WC and slab-EC, which were the inputs to irrigation control in T1, T2, T3, and T4; and, balances monitored the combined plant and rockwool slab weight loss, which was used for irrigation control in T5 and T6. For each of T1, T2, T3, and $\mathrm{T} 4$, the duration of slab-WC-based irrigation was $5 \mathrm{~min}$ during 24 Jan. to $9 \mathrm{Apr}$. 2005, 7 min during 10 Apr. to 12 May 2005, and 11 min during 13 May 2005 to the end; and the corresponding duration of slab-ECbased irrigation was 6,8 , and $12 \mathrm{~min}$, respectively. For T5 and T6, 10\%, 20\%, and $30 \%$ extra water (over the amount of water lost by evapotranspiration) was applied during the three previously mentioned periods. Thus, the irrigation duration for $\mathrm{T} 5$ during the three previously mentioned periods was 5 $\min 47 \mathrm{~s}, 6 \min 18 \mathrm{~s}$, and $6 \min 50 \mathrm{~s}$, respectively. The corresponding irrigation duration for T6 was $4 \min 8 \mathrm{~s}, 4 \min 30 \mathrm{~s}$, and $4 \mathrm{~min} 53 \mathrm{~s}$, respectively. A common irrigation practice was initially followed for all plots until the irrigation treatments were implemented on 24 Jan. 2005, i.e., $10 \mathrm{~d}$ after planting (DAP), when the plants had developed proper anchorage with the slab and sufficient leaf area. The irrigation control devices, namely the four Grodan ${ }^{\circledR}$ water content meters for $\mathrm{T} 1, \mathrm{~T} 2, \mathrm{~T} 3$, and $\mathrm{T} 4$ and the two "balances" for T5 and T6, were installed in one of eight replicate plots within each treatment. Irrigation decisions and the amount of water applied in each particular irrigation event in all of the eight replications were controlled on the basis of the pertinent information (slab-WC and slab-EC for T1T4 and weight loss for T5-T6) gathered from the single replicate of each treatment where the irrigation control device was installed. That meant both the number of irrigations and the amount of water applied to all eight replicate plots within each treatment were essentially the same.

Water use. Water use by the plants was estimated as the difference between the amount of water applied through irrigation and that leached out of the medium. Water use efficiency was estimated as the ratio of marketable fruit weight to either the amount of water applied through irrigation or that used by the plants.

Fruit yield. Fruit from each plot (four plants/plot) was harvested twice a week and graded into various marketable and unmarketable grades according to Ontario commercial standards (Ontario Ministry of Agriculture and Food, 1987). Fruit number and weight in each grade were recorded. Marketable tomato had three different size grades: extra large and large and small with fruit diameters of greater than 75,55 to 75 , and 40 to $55 \mathrm{~mm}$, respectively. In addition, there were commercial (based on shape) and No. 2 grades in marketable tomato. Unmarketable tomatoes were graded into four principal classes such as blossomend-rot, cat-faced, cracked, and hollow; the unmarketable fruit that did not fit into any of these four classes were recorded as "others."

Fruit quality. Fruit quality was evaluated at 115 DAP; various fruit quality attributes, namely fruit dry matter, $\mathrm{EC}, \mathrm{pH}$, and soluble solids content, were determined. The fruits were diced and either dried at $70{ }^{\circ} \mathrm{C}$ for measuring their dry matter (total solid) content or 
homogenized with a fruit blender to determine $\mathrm{pH}, \mathrm{EC}$, and soluble solids. The EC and $\mathrm{pH}$ of the homogenized fruit juice were determined with Hanna DIST ${ }^{\circledR} 5$ and Hanna pHep ${ }^{\circledR}$ (Hanna Instruments, Lavel, Quebec, Canada), respectively, and its soluble solids content was determined with a portable digital refractometer (model PR-101; Atago Co., Tokyo). At 126 DAP, fruit firmness was measured with an Instron Model 4411 Texture Machine (Instron Canada, Burlington, Ontario, Canada) using a constant area compression test of a pericarp disk (10 $\mathrm{mm}$ in diameter) sampled on the equator of tomato fruit at the pink stage.

Gas exchange. Leaf photosynthesis and transpiration were measured at 94 DAP (at noon) on the fifth youngest fully expanded leaf with a LI-6400 portable photosynthesis system (LI-COR, Lincoln, NE). The measurements were conducted at $350 \mathrm{ppm}$ of $\mathrm{CO}_{2}$ concentration, $1000 \mu \mathrm{mol} \cdot \mathrm{m}^{-2} \cdot \mathrm{s}^{-1}$ of photosynthetic photon flux density, $25{ }^{\circ} \mathrm{C}$ leaf temperature, and $65 \%$ ambient $\mathrm{RH}$.

Root growth. Root growth of tomato at 143 and 203 DAP was assessed using photographs of the appearance and abundance of roots at the bottom of the slab and then through qualitative indexing of the abundance and color of coarse and fine roots in three different portions (i.e., top, middle, and bottom) of the rockwool slab. Both root abundance and root color were evaluated on a 0 to 4 scale with 4 representing the most in abundance and for the whitest in color.
Statistical analysis. Statistical analysis was performed using the generalized linear model of SAS 8.02 (SAS, 1999). Treatment means were separated with the least significant difference test if the main treatment effect were significant at the $5 \%$ level in the analysis of variance.

\section{Results and Discussion}

Diurnal distribution of irrigation events. Irrigation frequency in the two weight-based treatments (T5 and T6) was determined solely by plant-water-use (PWU). In the other four treatments (T1, T2, T3, and T4), irrigation frequency was largely dictated by PWU, but in addition, it was also influenced by the

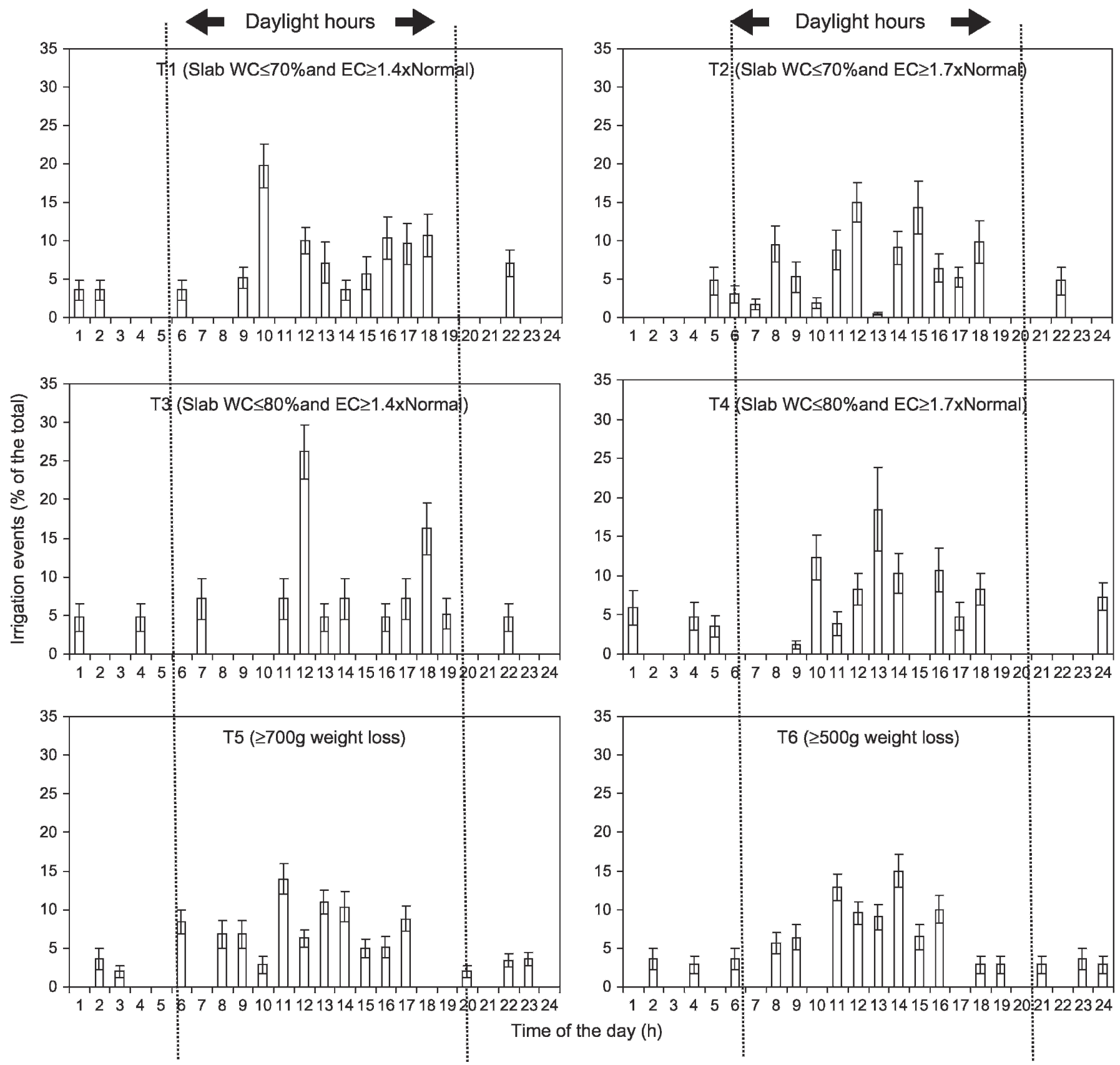

Fig. 1. Histogram of irrigation events through a day, by irrigation control treatment, as a percentage of the daily total. Vertical bars indicate SE of the mean; data averaged over $28 \mathrm{~d}$. 
slab-WC, slab-EC, and the hydraulic properties of the media. A histogram of all irrigation events recorded over a 28 -d period from 70 to 97 DAP is illustrated in Figure 1. Because the daily total number of irrigation events for the six treatments was different, the percentage of occurrence at different hours of the day was used rather than the absolute number of events to display the diurnal distribution of irrigation events with the different irrigation treatments. With all six irrigation control strategies, more than $80 \%$ of the total daily irrigation events occurred during the daylight hours (from $5 \mathrm{AM}$ to $7 \mathrm{PM}$ ). Furthermore, within the daylight hours, a majority of the irrigation events (above $60 \%$ of the total daily irrigation events) occurred during the late morning to early afternoon (9 AM to 4 PM). The nighttime irrigation events with $\mathrm{T} 1, \mathrm{~T} 2, \mathrm{~T} 3$, and $\mathrm{T} 4$ ranged from $10 \%$ to $22 \%$ of the total daily watering events; the corresponding range for T5 and T6 was $13 \%$ to $15 \%$. The results presented here clearly suggest that all of the six irrigation control strategies responded primarily to the PWU.

Slab-water content and slab-electrical conductivity. The daily mean slab-WC at different DAP with T1, T2, T3, and T4 (Fig. 2 ) reflects a clear separation between the two treatment groups initiating irrigation at slabWC $70 \%$ or less (T1 and $\mathrm{T} 2$ ) and slab-WC $80 \%$ or less (T3 and T4). Generally, the daily mean slab-WC (based on 24-h data, recorded at 15-min interval) was higher than that based on day time data with any given treatment. Across the season, the 24-h mean slab-WC with T1 and $\mathrm{T} 2$ ranged from $75 \%$ to $85 \%$, whereas the same with T3 and T4 ranged from $85 \%$ to $95 \%$. Within a given treatment, the variation in daily mean slab-WC was principally determined by sunlight conditions and irrigation duration. On a cloudy day, a higher daily mean slab-WC was registered than on a sunny day and a longer irrigation duration was associated with a higher daily mean slab-WC (data not shown).

There was a higher frequency of irrigation events triggered by EC with a higher slab-EC set point at any given slab-WC set point (i.e., $\mathrm{T} 2>\mathrm{T} 1$ and T4 > T3; Table 1); and the ECbased irrigations in any given treatment often occurred before the slab-WC dropped to its set point (data not shown), keeping the slab$\mathrm{WC}$ at a high level. As a result, treatment T2 had a higher daily mean slab-WC than T1 and T4 had higher daily mean slab-WC than T3 (Fig. 2).

The daily mean slab-EC was clearly higher with a higher slab-EC set point, i.e., $\mathrm{T} 2>\mathrm{T} 1$ and $\mathrm{T} 4>\mathrm{T} 3$ (Fig. 2). Within a given slab-EC set point, a higher slab-WC set point
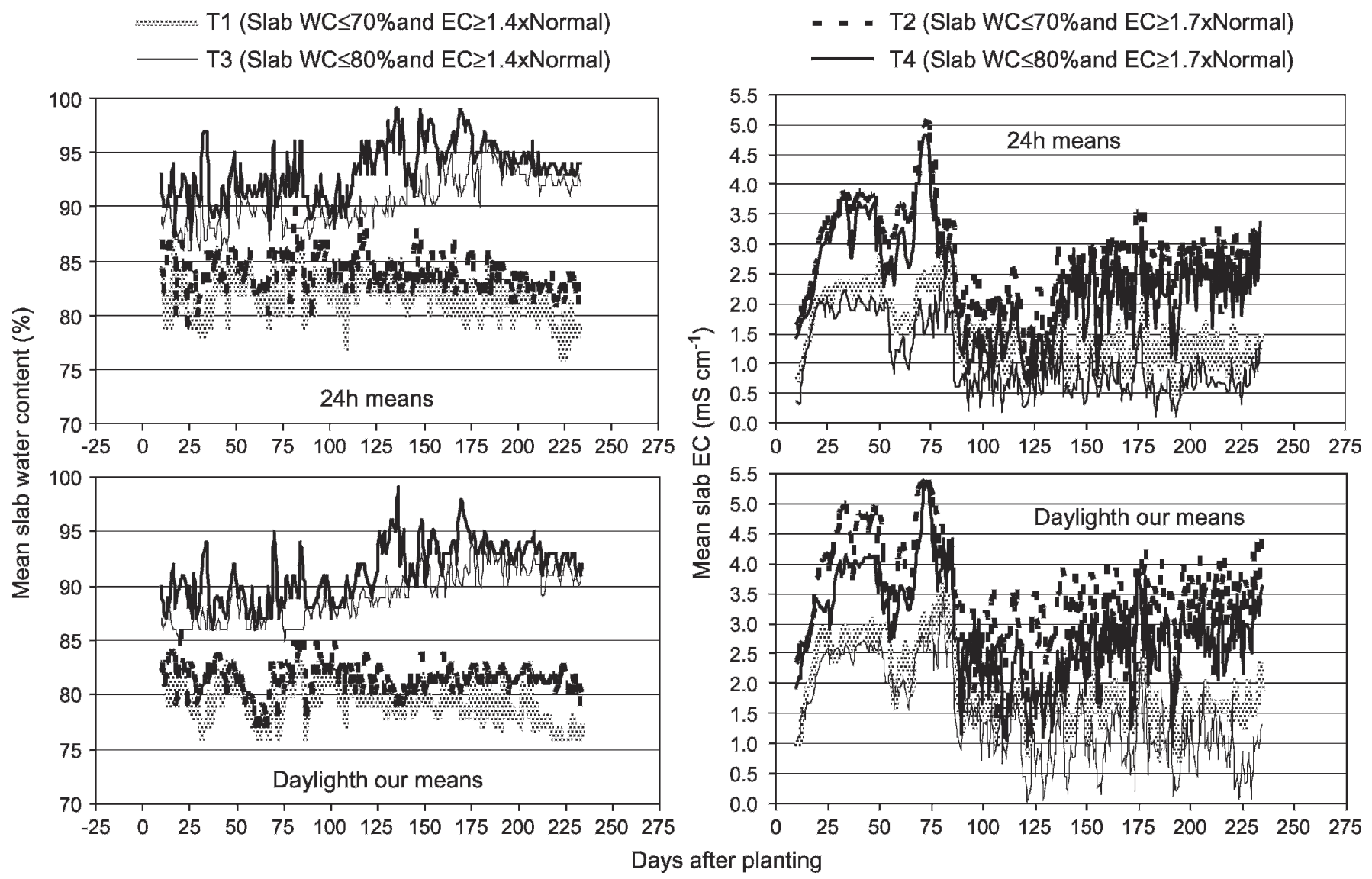

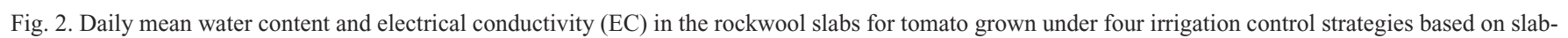
water content and slab-EC.

Table 1. Irrigation events and water use patterns of rockwool-grown greenhouse tomato under six irrigation control strategies (1 Feb. to 5 Sept. 2005).

\begin{tabular}{|c|c|c|c|c|c|c|}
\hline \multirow{2}{*}{ Irrigation treatments $\mathrm{s}^{\mathrm{z}}$} & \multicolumn{3}{|c|}{ Daily mean irrigation events } & \multirow{2}{*}{$\begin{array}{c}\text { Mean irrigation } \\
\text { water applied } \\
\text { (L/plant/day) }\end{array}$} & \multirow{2}{*}{$\begin{array}{l}\text { Mean water use } \\
\text { (L/plant/day) }\end{array}$} & \multirow{2}{*}{$\begin{array}{c}\text { Leach } \\
\text { factor }(\%)\end{array}$} \\
\hline & \multicolumn{2}{|c|}{ Irrigation triggered by } & Total & & & \\
\hline $\mathrm{T} 1: \mathrm{WC} \leq 70 \%$ or $\mathrm{SEC} \geq 1.4 \times$ normal & $4.00(81)$ & $0.95(19)$ & 4.95 & 2.06 & 1.51 & 27 \\
\hline $\mathrm{T} 3: \mathrm{WC} \leq 80 \%$ or $\mathrm{SEC} \geq 1.4 \times$ normal & $4.79(83)$ & $0.95(17)$ & 5.74 & 2.24 & 1.51 & 33 \\
\hline $\mathrm{T} 4: \mathrm{WC} \leq 80 \%$ or $\mathrm{SEC} \geq 1.7 \times$ normal & $3.41(67)$ & $1.67(33)$ & 5.08 & 2.13 & 1.41 & 34 \\
\hline T5: $\geq 700 \mathrm{~g}$ weight loss & - & - & 8.67 & 2.29 & 1.22 & 47 \\
\hline $\mathrm{T} 6: \geq 500 \mathrm{~g}$ weight loss & - & - & 11.34 & 2.17 & 1.50 & 31 \\
\hline
\end{tabular}

$\mathrm{WC}=$ water content in the slab; $\mathrm{SEC}=$ slab EC; normal $=$ normal feed nutrient solution electrical conductivity as recommended in the seasonal fertigation schedule for spring-summer tomato crop by Papadopoulos (1998). 
had a lower daily mean slab-EC, i.e., T3 $<$ T1 and $\mathrm{T} 4<\mathrm{T} 2$. This was probably a result of greater irrigation frequency and higher leach factor (i.e., the ratio of leached water to irrigation water) at a higher slab-WC set point at any given slab-EC set point.

With the two weight-based systems (T5 and T6), slab-WC and slab-EC were manually recorded only once a day (around noon) across the growing season using a portable Grodan $^{\circledR}$ WC-meter. These data are presented in Figure 3. Treatment T5, which allowed $700 \mathrm{~g}$ weight loss before irrigation, dried down to $50 \%$ slab-WC as compared to a $500 \mathrm{~g}$ weight loss before irrigation. There was, however, no large difference between T5 and T6 with respect to the uppermost slab-WC, because they were both irrigated up to the same target point (i.e., $10 \%, 20 \%$, or $30 \%$ higher than the amount lost depending on the stages of the crop). The slab-EC with T5 was slightly lower than with T6 owing to its higher leaching percentage.

Irrigation events, irrigation water applied, and water use. In general, the higher the slabWC set point, the higher were the daily mean number of irrigation events and the daily mean amount of irrigation water applied at any given slab-EC set point (i.e., T3 $>$ T1 and T4 $>$ T2; Table 1), indicating that more irrigation water minimum of $65 \%$ with T6, which allowed

was needed to maintain the slab-WC at a higher level. At any given slab-WC set point, a higher slab-EC set point had a lower total number of irrigation events as well as a lower amount of irrigation water than the lower slabEC set point (i.e., T $2<\mathrm{T} 1$ and $\mathrm{T} 4<\mathrm{T} 3$; Table $1)$, indicating that water uptake was probably slow as a result of higher slab-EC even when slab-WC was comparable. The daily mean amount of irrigation water applied with $\mathrm{T} 1$, $\mathrm{T} 2$, T3, and T4 ranged from 1.84 to 2.24 L/plant, whereas the corresponding number of daily mean irrigation events ranged from 4.07 to 5.74 (Table 1 ).

The other two treatments which applied irrigation after 700 and $500 \mathrm{~g}$ weight loss (T5 and T6, respectively) had considerably different daily mean number of irrigation events (8.64 and 11.34 , respectively), whereas the daily mean amount of irrigation water was similar (2.29 and $2.17 \mathrm{~L} /$ plant, respectively; Table 1).

The percentage of irrigation water that was leached (leach factor) was similar $(27 \%$ to $34 \%$ ) with all treatments except for $\mathrm{T} 5$, in which it was $47 \%$ (Table 1); a higher leach factor was recorded with T5 than with T6 (Table 1). Available literature suggests that intensive greenhouse crop production in rockwool and other soilless media requires a leach factor in the range of $25 \%$ to $50 \%$ depending on the EC of the feed solution and
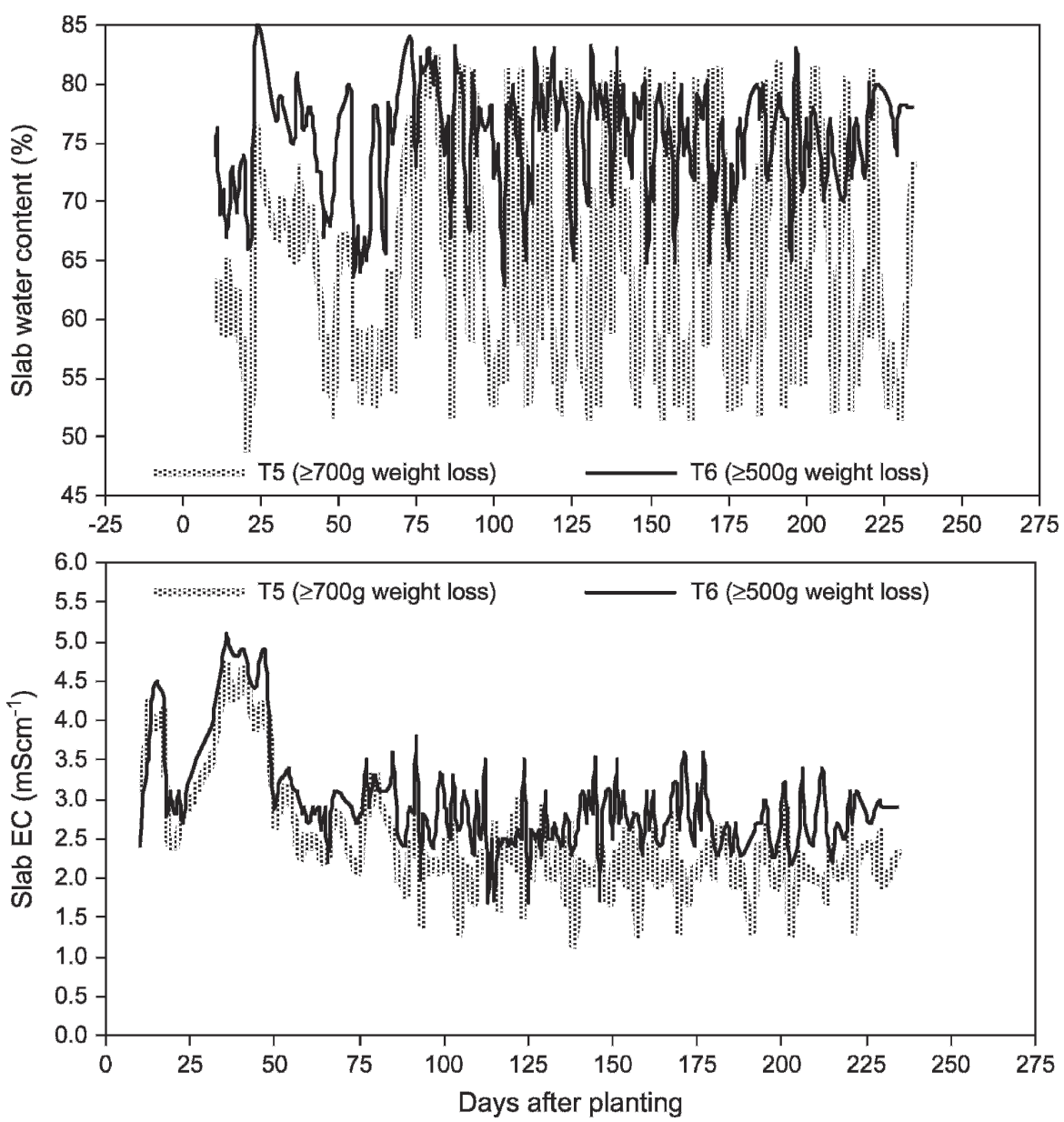

Fig. 3. Water content and electrical conductivity in rockwool slabs for tomatoes under two weight-based irrigation control strategies. climatic conditions (Van Os, 1995). The irrigation set points are normally adjusted in commercial greenhouses to provide variable volumes of leachate throughout the day. Growers generally target very little leachate in the morning and increase the leachate up to $40 \%$ in the bright afternoons (Shelford et al., 2004). The daily mean water use (irrigation water minus leached water) with the different treatments ranged from 1.22 to $1.51 \mathrm{~L} /$ plant per day (Table 1). Adams (1989) reported the daily water uptake by a fruiting tomato plant as $1.4 \mathrm{~L}$. The leachate EC followed the same trend as the trends discussed earlier for slab$\mathrm{EC}$ (i.e., T2 > T1; T4 > T3; and T6 > T5) (data not shown).

Seasonal variation in yield. Early in the season (69 to 143 DAP; 21 harvests), both the number and weight of marketable fruit with $\mathrm{T} 1, \mathrm{~T} 2$, and $\mathrm{T} 6$ were similar but significantly higher than those of the rest of the treatments (Fig. 4). During both mid- (143 to 206 DAP; 18 harvests) and late (206 to 234 DAP; five harvests) seasons, the number and weight of marketable fruit were the lowest with T5 (Fig. 4), whereas there was no significant difference among T1, T2, T3, T4, and T6. The cumulative number and weight of marketable fruit for early (21 harvests) and all season (44 harvests) followed almost the same trend; i.e., treatments $\mathrm{T} 1, \mathrm{~T} 2$, and $\mathrm{T} 6$ resulted in the highest marketable yield, whereas there was no significant difference among T3, T4, and T5 (data not shown).

Fruit grade distribution. Early in the season (69 to 143 DAP; 21 harvests), the irrigation strategies had significant effects on both number and weight of large (Fig. 5) and commercial (data not shown) fruit; the weight of extra large fruit was also affected significantly by the irrigation strategies (Fig. 5 ). The extra large fruit weight with $\mathrm{T} 1, \mathrm{~T} 2$, and $\mathrm{T} 6$ was similar but significantly higher than with T3, T4, and T5. Both the number and weight of large fruit with $\mathrm{T} 1, \mathrm{~T} 2$, and T6 were significantly higher than those of T3, T4, and T5 (Fig. 5). Thus, higher marketable yield early in the season with T1, T2, and T6 (as discussed previously) was attributable largely to extra large and large fruit.

Based on the total seasonal marketable yield (from all 44 harvests), irrigation strategies exerted significant effects on the number and weight of extra large and large fruit (Fig. 5) but had no significant effects on the small, commercial, and No. 2 grades (data not shown). The number and weight of extra large fruit were similar with T1, T2, T4, and T6 but significantly higher than those with $\mathrm{T} 3$ and $\mathrm{T} 5$. The number and weight of large fruit with $\mathrm{T} 1$, $\mathrm{T} 2$, T3, and T6 were similar but significantly higher than those with T4 and T5. The combined contribution of extra large and large fruit weight versus other marketable grades was calculated in terms of percentage of total marketable fruit weight. As far as early yield is concerned, treatments T1, T2, and T6 resulted in a higher proportion of their marketable yield contributed by extra large and large fruit $(95 \%$ to $96 \%$ ) as compared with $\mathrm{T} 3, \mathrm{~T} 4$, and $\mathrm{T} 5$ ( $92 \%$ to $94 \%$ ) (data not shown). Late in the 

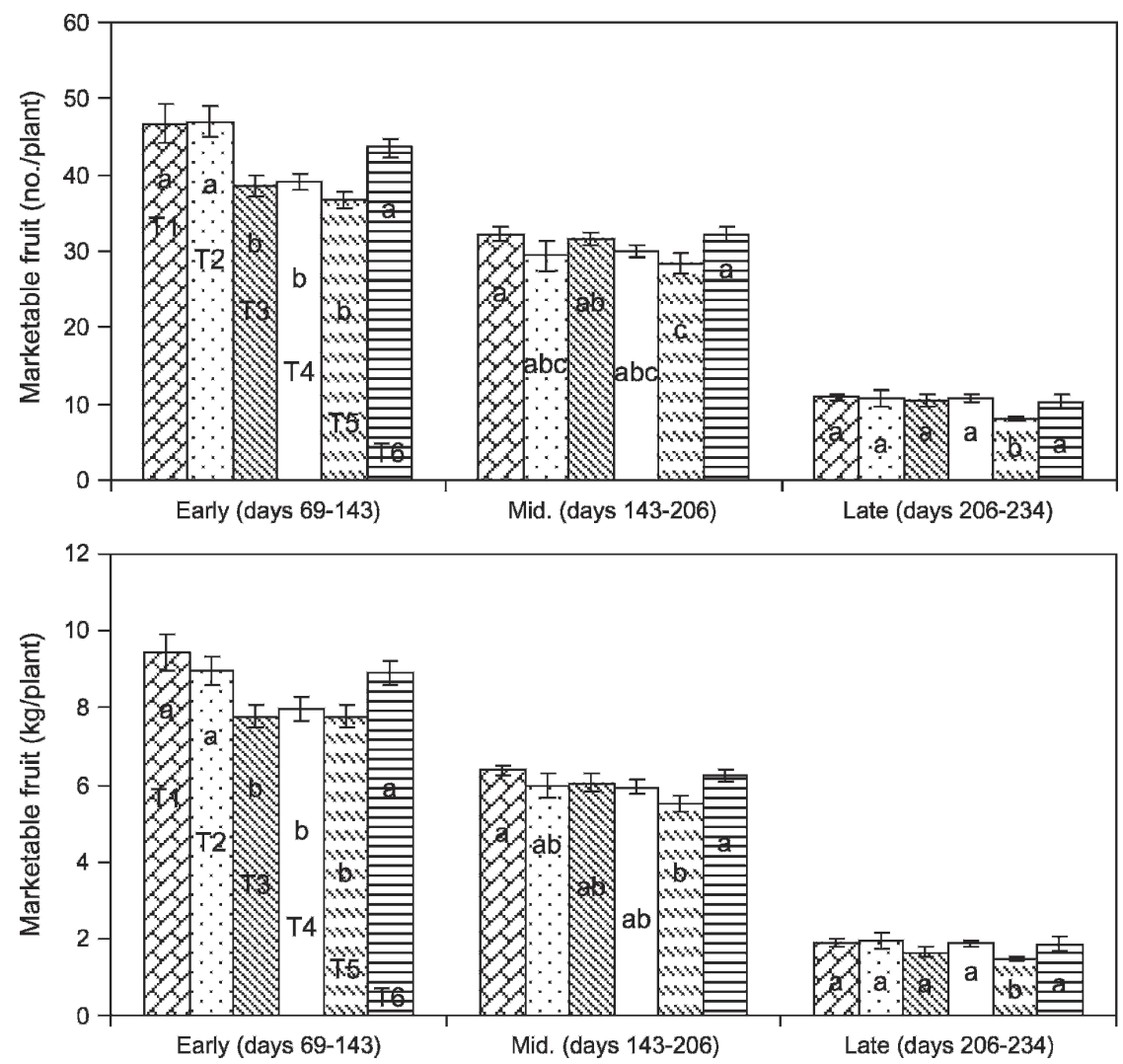

Fig. 4. Early, mid-, and late season marketable yield of rockwool-grown greenhouse tomato as influenced by six irrigation control strategies. Vertical bars indicate sEs. Columns within a group with the same letter are not significantly different at the $5 \%$ level of significance. season, all six treatments had a similar share of extra large and large fruit in marketable yield. In the case of total seasonal marketable yield, the irrigation treatments showed a trend very similar to that observed with the early yield with respect to the contribution of extra large and large grades (data not shown). Thus, the "all season" marketable fruit grade distribution also indicated the superiority of $\mathrm{T} 1, \mathrm{~T} 2$, and $\mathrm{T} 6$ over T3, T4, and T5 as observed early in the season.

Fruit quality. Irrigation strategies had significant effects only on the content of soluble solids in the fruit. Therefore, we have limited the presentation and discussion to this fruit quality trait only. As depicted in Figure 6 , T1 had significantly higher soluble solids than T4, T5, and T6, whereas T2 and T3 had soluble solids content similar to T1. The results of the fruit firmness test (Fig. 6) show that the fruit from the irrigation strategy with a higher slab-EC set point had significantly higher firmness than its lower slab-EC counterpart at any given slab-WC set point (i.e., $\mathrm{T} 2>\mathrm{T} 1$ and T4 > T3). On the contrary, the slab-WC set points had no significant effect on fruit firmness at any given slab-EC set point (i.e., $\mathrm{T} 1=\mathrm{T} 3$ and $\mathrm{T} 2=\mathrm{T} 4$ ). The two weight-based systems did not differ significantly in their fruit firmness (i.e., T5 = T6). The firmer fruits in T2 over T1 and T4 over T3 (Fig. 6) may be attributed to their relatively high slab-EC. It has been reported that fruit grown under high EC conditions tends to
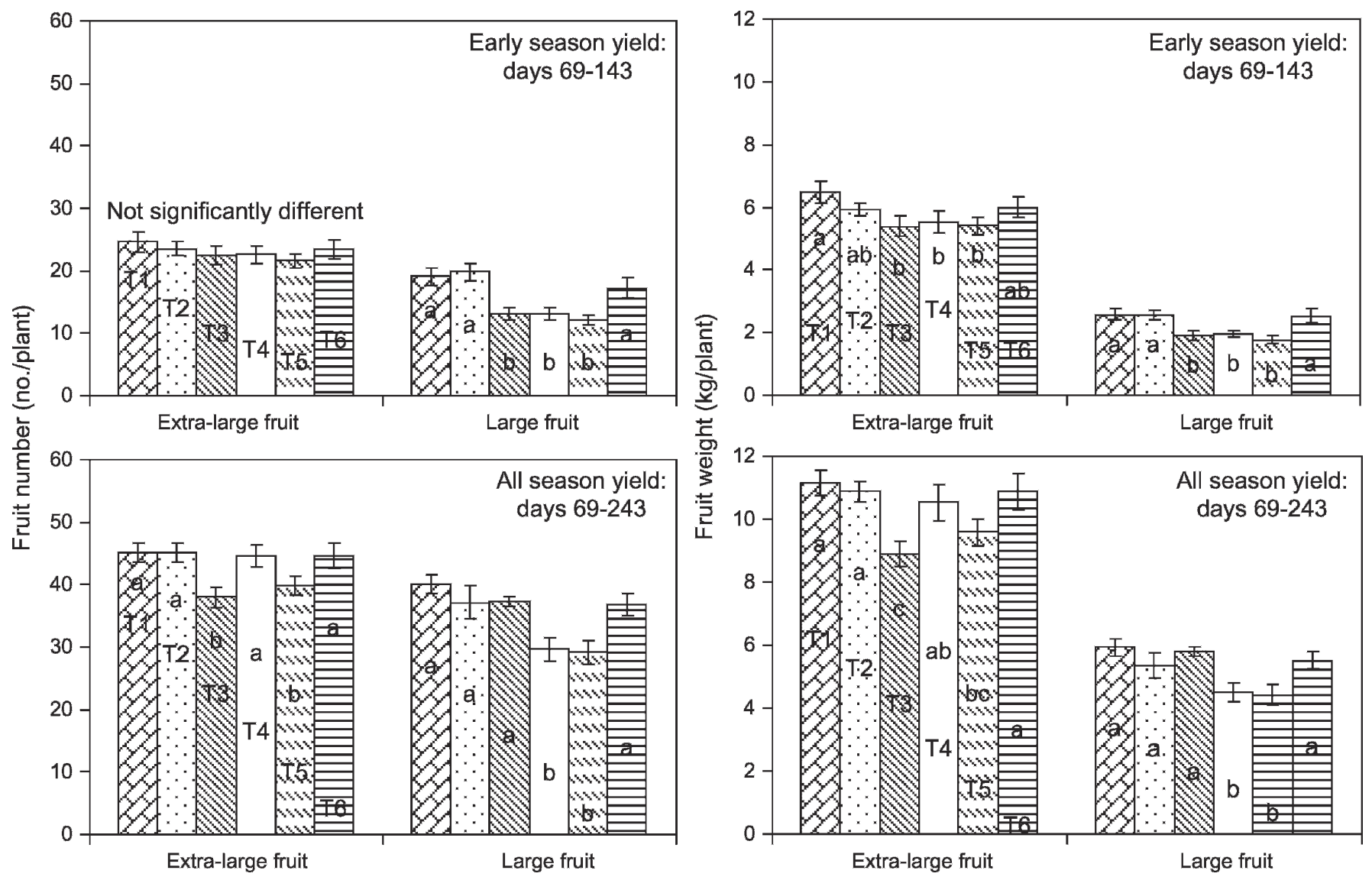

Fig. 5. Yield of extra large and large marketable fruit of rockwool-grown greenhouse tomato as influenced by six irrigation control strategies. Vertical bars indicate sEs. Columns within a group with the same letter are not significantly different at $5 \%$ level of significance. 
have a thicker and more resistant cuticle (Chrétien et al., 2000; Ho and Adams, 1995) as well as a low turgor pressure because of reduced water absorption by the roots (Ho and Adams, 1995).

Water use efficiency. Water use efficiency (WUE) of tomato $\left(\mathrm{g} \cdot \mathrm{L}^{-1}\right)$ was estimated as the ratio of marketable yield (g/plant) to either irrigation water applied (WUE-applied) or water used (irrigation water minus leached water, WUE-used). The results (Fig. 7) show that WUE-applied was higher with a $70 \%$ slab-WC set point than with an $80 \%$ slab-WC at any given slab-EC set point (i.e., T1 $>$ T3 and $\mathrm{T} 2>\mathrm{T} 4)$. At any given slab-WC set point, a higher slab-EC set point also resulted in a higher WUE-applied (i.e., T2 > T1 and T4 > T3). Between the two weight-based treatments, T6 had a greater WUE-applied than T5. In the cases of the three previously mentioned water efficient treatments, namely $\mathrm{T} 2, \mathrm{~T} 1$, and $\mathrm{T} 6$, the nutrient solution required to produce $1 \mathrm{~kg}$ of marketable fruit was 23.8 , 25.0, and $27.8 \mathrm{~L}$, respectively.

Like the WUE-applied, the WUE-used followed the trend of $\mathrm{T} 1>\mathrm{T} 3$ and $\mathrm{T} 2>\mathrm{T} 4$, confirming the superiority of a $70 \%$ slab-WC set point at any given slab-EC set point (Fig. 7). When compared between the two slab-EC set points, the WUE-used showed the trend: $\mathrm{T} 2>\mathrm{T} 1$ and $\mathrm{T} 4>\mathrm{T} 3$, indicating an improvement in WUE with a higher slab-EC set point.

Gas exchange. In general, there was a highly significant positive correlation between leaf photosynthesis and transpiration (Fig. 8), indicating that irrigation strategies had similar effects on these two plant functions. Treatment T2 had the highest leaf photosynthesis (Fig. 8). Treatments T1 and T6 had similar leaf photosynthesis, which was significantly higher than with T3, T4, and T5. Furthermore, there was no significant difference among the leaf photosynthesis with T3, T4, and T5. Treatments T1 and T2 had similar leaf transpiration, which was significantly higher than with $\mathrm{T} 3, \mathrm{~T} 4$, and T5 (Fig. 8). Among T3, T4, and T5, the leaf transpiration followed the trend of $\mathrm{T} 4>\mathrm{T} 5>$ T3. Treatment T6 had leaf transpiration similar to $\mathrm{T} 1, \mathrm{~T} 2$, and $\mathrm{T} 4$. In summary, a $70 \%$ slab-WC set point resulted in higher leaf photosynthesis and transpiration than a $80 \%$ set point at any given slab-EC set point. Leaf photosynthesis increased with a higher slabEC set point at the $70 \%$ slab-WC set point, but not at $80 \%$. On the contrary, leaf transpiration was higher with a higher slab-EC set point at the $80 \%$ slab-WC set point but not at $70 \%$. Between the two weight-based systems, T6 resulted in higher leaf photosynthesis and transpiration than $\mathrm{T} 5$.

The reduction in the rate of transpiration in $\mathrm{T} 3$ and $\mathrm{T} 4$ relative to $\mathrm{T} 1$ and $\mathrm{T} 2$ could be the result of reduced water uptake, which might be attributed to inadequate oxygen availability for root respiration resulting from the presence of excess water (Holtman et al., 2005). On the other hand, a lower transpiration rate with $\mathrm{T} 5$ relative to $\mathrm{T} 6$ could be the result of excessive drop of water content in T5 (down to $50 \%$ to $55 \%$ ) and the consequent
09 May 2005; 115 days after planting
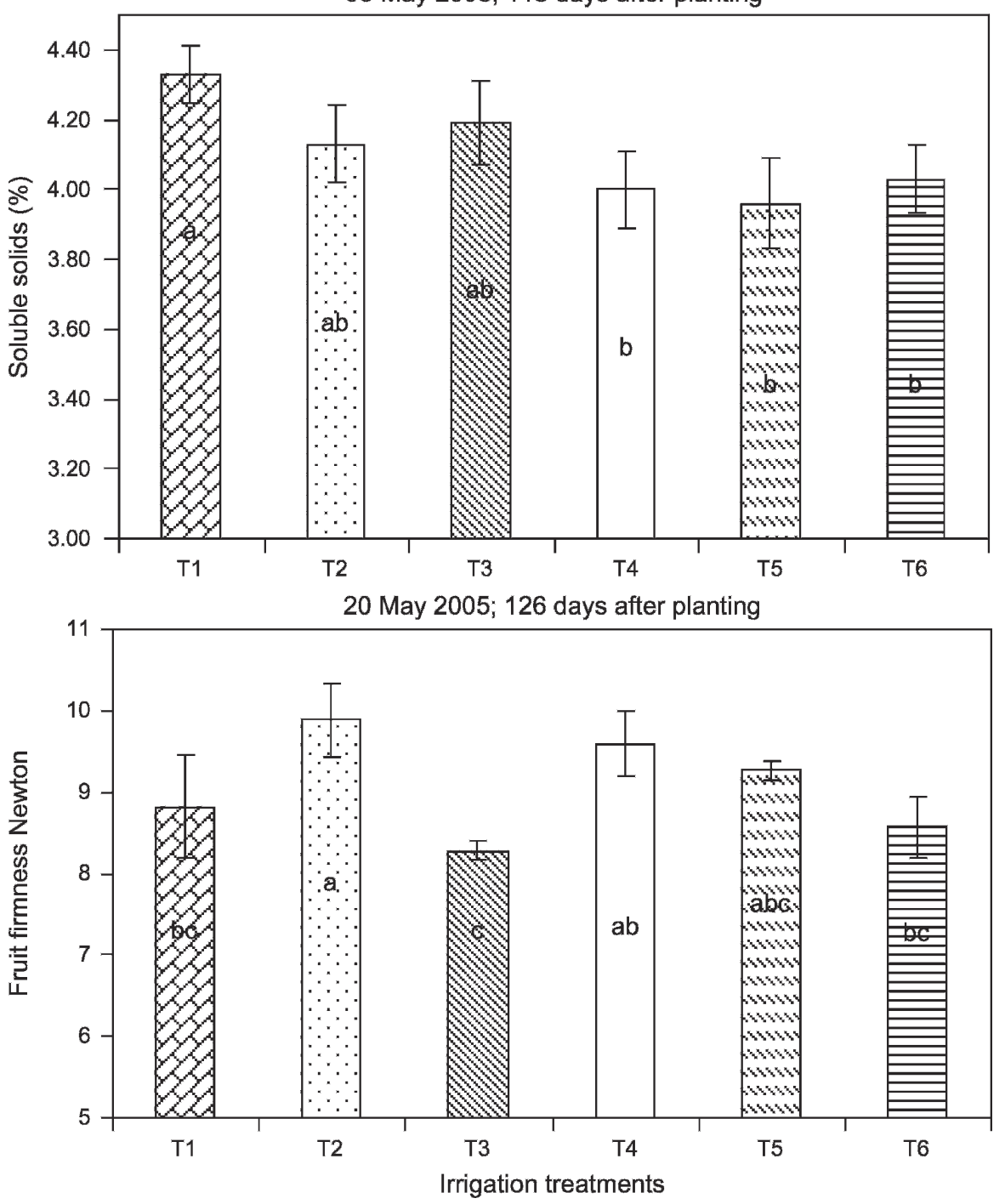

Fig. 6. Soluble solids content and firmness of rockwool-grown greenhouse tomato fruit as influenced by six irrigation control strategies. Vertical bars indicate SES. Columns with the same letter are not significantly different at $5 \%$ level of significance.

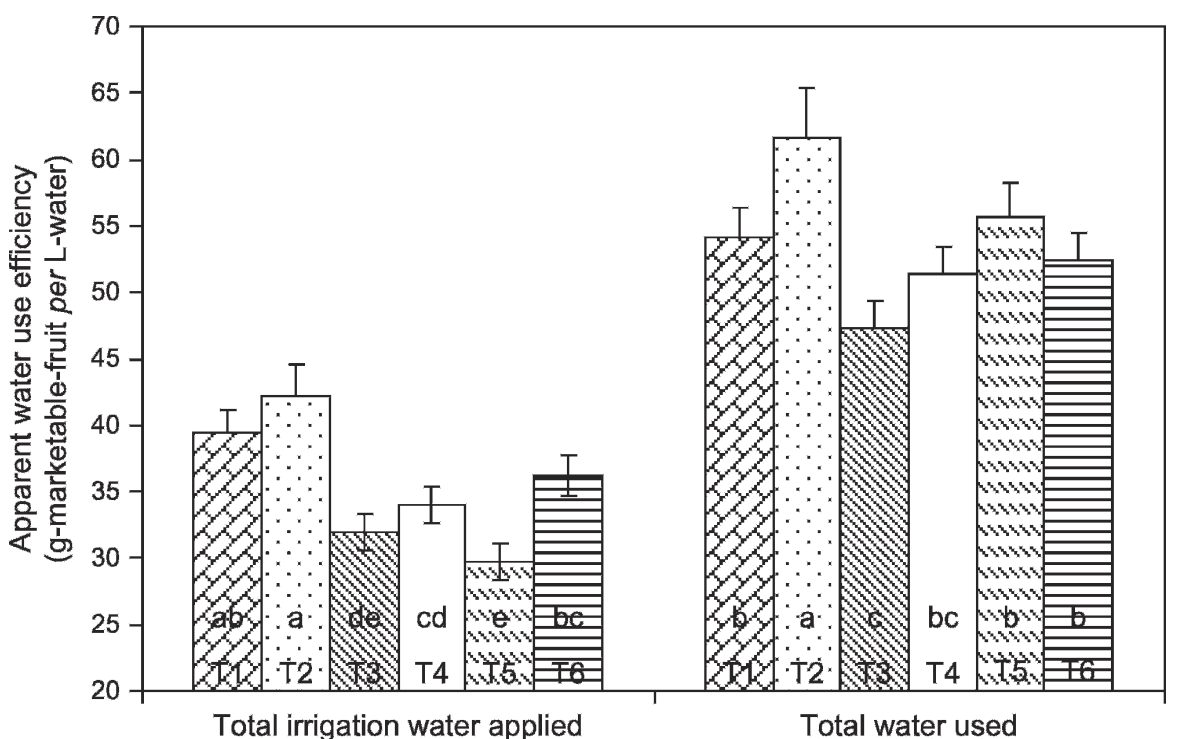

Fig. 7. Water use efficiency of rockwool-grown greenhouse tomato as influenced by six irrigation control strategies. Vertical bars indicate ses. Columns with the same letter are not significantly different at the $5 \%$ level of significance. 

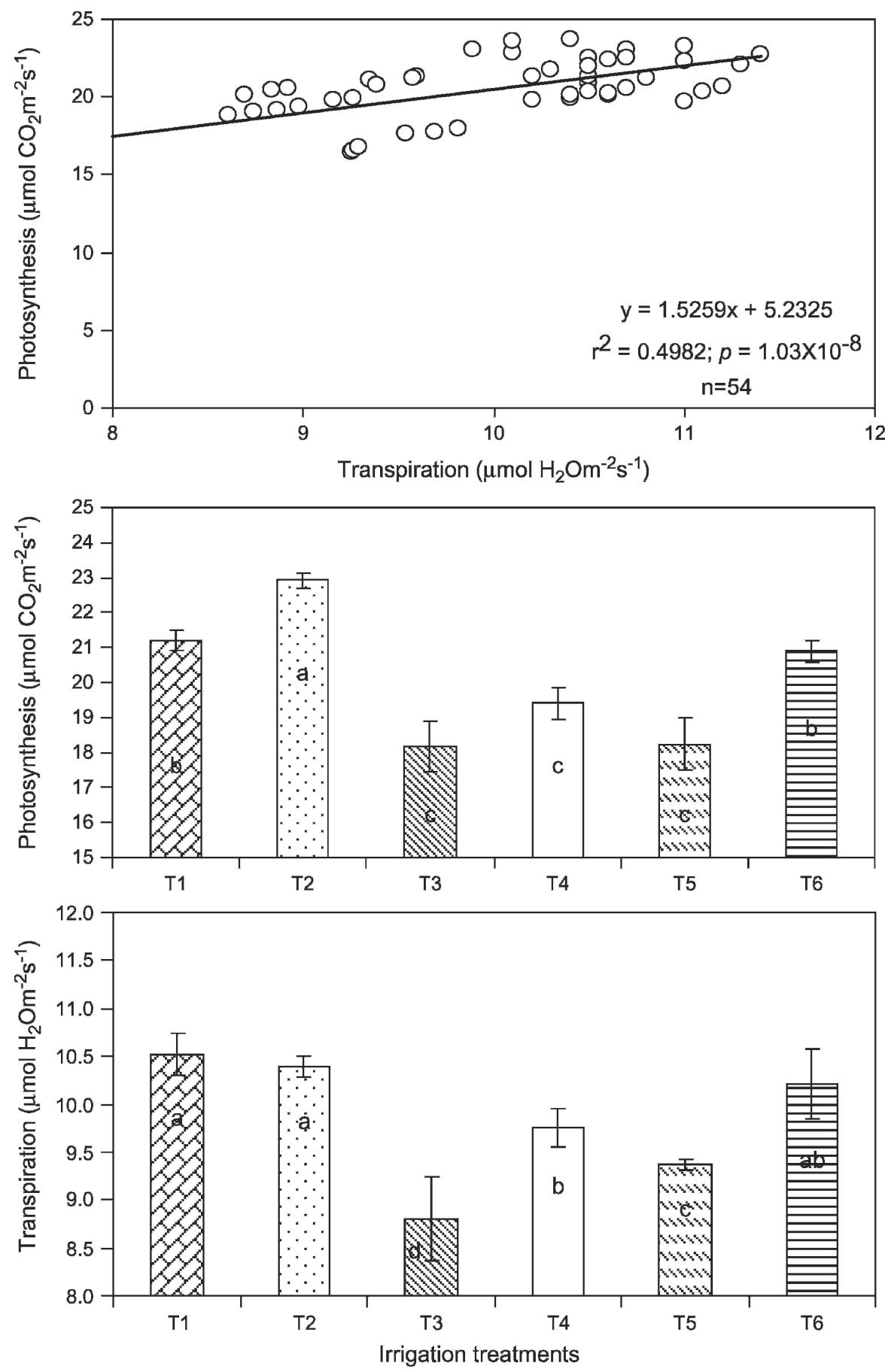

Fig. 8. Leaf photosynthesis and transpiration of rockwool-grown greenhouse tomato at $94 \mathrm{~d}$ after planting (18 Apr. 2005) as influenced by six irrigation control treatments. Vertical bars indicate sEs. Columns with the same letter are not significantly different at $5 \%$ level of significance.

water and salt stress. Both leaf photosynthesis and transpiration showed significant positive correlations with early marketable yield (first 21 harvests, during 69 to 143 DAP) expressed in terms of either fruit number or fruit weight per plant (plots not shown). The values of correlation coefficient (r) were: $0.94^{* *}$ for early-marketable-fruitnumber versus photosynthesis; $0.85^{*}$ for early-marketable-fruit-weight versus photosynthesis; $0.87 *$ for early-marketable-fruitnumber versus transpiration; and $0.91^{* *}$ for early-marketable-fruit-weight versus transpiration, in which $*$ and $* *$ indicate $P$ values less than 0.05 and 0.01 , respectively. Leaf photosynthesis had a significant positive correlation also with the all season marketable fruit number $\left(\mathrm{r}=0.82^{*}\right)$ and weight $(\mathrm{r}=$ $0.82 *)$. However, leaf transpiration had a significant positive correlation with the total seasonal marketable fruit weight $\left(\mathrm{r}=0.86^{*}\right)$ but not with fruit number $(\mathrm{r}=0.77, P=0.08)$. Positive relationships of economic yield to the rates of transpiration have been reported (Garrity et al., 1982; Hanks, 1974). The present results support the contention that maximum production of horticultural crops requires the maintenance of a balance be- tween processes favoring production, e.g., continued leaf area expansion and open stomata, and processes minimizing damaging water stresses that could reduce photosynthesis (Jones and Tardieu, 1998).

Root growth. As depicted on Plate 1, irrigation treatments resulted in remarkably different root growth at 143 DAP. Irrigation strategies based on a $70 \%$ slab-WC set point (T1 and T2) resulted in substantially better root growth over the ones based on $80 \%$ slabWC (T3 and T4). The effect of the two slabEC set points at either $70 \%$ or $80 \%$ (i.e., either T1 versus $\mathrm{T} 2$ or $\mathrm{T} 3$ versus $\mathrm{T} 4$ ) on the appearance of roots at the bottom of the slab was not very clear except that a lower slabEC set point (i.e., T1 and T3) was associated with apparently whiter roots. Between the two weight-based treatments, T6 had better root growth than T5 (Plate 1). A similar trend in root growth at the bottom of the slabs in relation to various irrigation strategies was also seen at 203 DAP (Plate 1).

The effects of various irrigation strategies on root growth at 143 DAP was further investigated using qualitative indices for root abundance and root color. Both root abundance and root color at three different positions (top, middle, and bottom) in a slab were evaluated on a 0 to 4 scale as described in Table 2. The irrigation treatments had no significant effect on root abundance and root color at the top one-third portion of the slab, but they did affect both root abundance and color at the middle (one-third) and bottom (one-third) portions of the slab (Table 2).

In the middle of the slab, the abundance of coarse roots with $\mathrm{T} 1, \mathrm{~T} 2, \mathrm{~T} 5$, and $\mathrm{T} 6$ was significantly greater than with $\mathrm{T} 3$ and $\mathrm{T} 4$ (Table 2); the abundance of fine roots was generally greater than the coarse roots. Comparison of various irrigation strategies with respect to the abundance of fine roots also indicated the superiority of T1, T2, and T6 over T3 and T4. Root color (whiter is better) in the middle also followed a trend similar to root abundance.

At the bottom of the slab, T1 and T2 had a significantly greater abundance of coarse roots than T3, T4, and T5 (Table 2). There was, however, no significant difference in the abundance of coarse roots among T3, T4, T5, and T6. The abundance of fine roots was significantly greater with $\mathrm{T} 1, \mathrm{~T} 2, \mathrm{~T} 5$, and T6 than with T3. There was, however, no significant difference among T2, T4, T5, and $\mathrm{T} 6$ or between $\mathrm{T} 3$ and $\mathrm{T} 4$. Treatments $\mathrm{T} 5$ and T6 had the whitest roots at the bottom of the slab. Root whiteness seemed to be associated with a low slab-EC.

Root growth appearance (Plate 1), root abundance, and root color (Table 2), as discussed previously, reveal that proper irrigation management brought about a better root establishment in the slabs. The better root growth in the slabs irrigated at $70 \%$ slabWC over ones irrigated at $80 \%$ slab-WC as observed in this study could be attributed to greater oxygen availability in the rhizosphere. Numerous reports demonstrate that oxygen deficiency in the rhizosphere has 


\begin{tabular}{|c|c|c|c|c|c|c|}
\hline \multirow[t]{2}{*}{143 days after planting } & \multirow[t]{2}{*}{203 days after planting } & $\begin{array}{c}\text { Marketable } \\
\text { yield } \\
\text { (kg/plant) }\end{array}$ & $\begin{array}{l}\text { Photosynthesis } \\
\left(\mu \mathrm{mol} \mathrm{CO}_{2} \mathrm{~m}^{-2} \mathrm{~s}^{-1}\right)\end{array}$ & $\begin{array}{l}\text { Transpiration } \\
\left(\mu \mathrm{mol} \mathrm{H}_{2} \mathrm{O} \mathrm{m}^{-2} \mathrm{~s}^{-1}\right)\end{array}$ & $\begin{array}{l}\text { Leach } \\
\text { factor } \\
(\%)\end{array}$ & $\begin{array}{c}\text { Water use } \\
\text { efficiency } \\
\text { (g/L) }\end{array}$ \\
\hline & & $17.7 \pm 0.7 a$ & $21.20 \pm 0.31 b$ & $10.52 \pm 0.22 a$ & 27 & $39.5 \pm 1.6 \mathrm{ab}$ \\
\hline & & $16.8 \pm 1.0 \mathrm{ab}$ & $22.91 \pm 0.20 a$ & $10.40 \pm 0.11 a$ & 32 & $42.1 \pm 2.6 a$ \\
\hline & & $15.5 \pm 0.7 \mathrm{bc}$ & $18.17 \pm 0.72 c$ & $8.81 \pm 0.44 d$ & 33 & $31.87 \pm 1.4 \mathrm{de}$ \\
\hline & & $15.8 \pm 0.6 \mathrm{bc}$ & $19.40 \pm 0.45 c$ & $9.76 \pm 0.20 b$ & 34 & $34.07 \pm 1.4 \mathrm{~cd}$ \\
\hline & & $14.8 \pm 0.7 c$ & $18.23 \pm 0.74 c$ & $9.37 \pm 0.05 \mathrm{c}$ & 47 & $29.70 \pm 1.4 \mathrm{e}$ \\
\hline & & $17.0 \pm 0.7 a b$ & $20.90 \pm 0.31 b$ & $10.21 \pm 0.36 a b$ & 31 & $36.20 \pm 1.5 b c$ \\
\hline
\end{tabular}

Plate 1. Linkage of root growth, water uptake, gas exchange, and marketable yield of rockwool-grown greenhouse tomato under six irrigation control strategies. Means within a column followed by the same letter are not significantly different at the $5 \%$ level of significance.

Table 2. Effects of irrigation control strategy on root-growth ${ }^{\mathrm{z}}$ and distribution in greenhouse tomato grown on rockwool.

\begin{tabular}{|c|c|c|c|c|c|c|c|c|c|}
\hline \multirow[b]{3}{*}{ Irrigation treatments ${ }^{\mathrm{x}}$} & \multicolumn{9}{|c|}{ Location within the rockwool slab } \\
\hline & \multicolumn{3}{|c|}{ Top } & \multicolumn{3}{|c|}{ Middle } & \multicolumn{3}{|c|}{ Bottom } \\
\hline & Coarse & Fine & $\begin{array}{l}\text { Root }^{\mathrm{v}} \\
\text { Color }\end{array}$ & Coarse & Fine & $\begin{array}{l}\text { Root } \\
\text { Color }\end{array}$ & Coarse & Fine & $\begin{array}{l}\text { Root } \\
\text { Color }\end{array}$ \\
\hline $\mathrm{T} 1: \mathrm{WC} \leq 70 \%$ or $\mathrm{SEC} \geq 1.4 \times$ normal & 2.81 & 3.71 & 2.38 & $2.88 \mathrm{a}$ & $3.88 \mathrm{a}$ & $3.00 \mathrm{ab}$ & $3.13 \mathrm{a}$ & $4.00 \mathrm{a}$ & $3.13 \mathrm{bc}$ \\
\hline $\mathrm{T} 2: \mathrm{WC} \leq 70 \%$ or $\mathrm{SEC} \geq 1.7 \times$ normal & 2.63 & 3.19 & 2.75 & $2.75 \mathrm{ab}$ & $3.82 \mathrm{a}$ & $3.00 \mathrm{ab}$ & $2.94 \mathrm{a}$ & $3.69 \mathrm{ab}$ & $3.00 \mathrm{~cd}$ \\
\hline $\mathrm{T} 3: \mathrm{WC} \leq 80 \%$ or $\mathrm{SEC} \geq 1.4 \times$ normal & 2.75 & 3.56 & 2.75 & $2.56 \mathrm{bc}$ & $3.33 \mathrm{~b}$ & $2.63 \mathrm{c}$ & $2.50 \mathrm{~b}$ & $3.19 \mathrm{c}$ & $3.38 \mathrm{ab}$ \\
\hline $\mathrm{T} 4: \mathrm{WC} \leq 80 \%$ or $\mathrm{SEC} \geq 1.7 \times$ normal & 3.06 & 3.94 & 2.75 & $2.44 \mathrm{c}$ & $3.25 \mathrm{~b}$ & $2.63 \mathrm{c}$ & $2.44 \mathrm{~b}$ & $3.50 \mathrm{bc}$ & $2.81 \mathrm{~d}$ \\
\hline \multirow{2}{*}{$\begin{array}{l}\text { Fisher's protected least } \\
\text { significant difference }_{0.05}\end{array}$} & & & & & & & & & \\
\hline & $\mathrm{NS}^{\mathrm{u}}$ & NS & NS & 0.25 & 0.41 & 0.34 & 0.41 & 0.42 & 0.26 \\
\hline
\end{tabular}

${ }^{2}$ Root growth determined at $143 \mathrm{~d}$ after planting on 6 June 2005 .

${ }^{y}$ Means within a column followed by the same letter are not significantly different at $5 \%$ level of significance.

${ }^{x} \mathrm{WC}=$ water content in the slab; SEC = slab EC; normal = normal feed nutrient solution electrical conductivity as recommended in the seasonal fertigation schedule for spring-summer tomato crop by Papadopoulos (1998).

whoot abundance index: 0 = no root present; 1 = a few roots present; 2 = some/fair number of roots present; 3 = good/considerable number of roots present; $4=$ many/substantial number of roots present. Coarse roots are thick roots that are good for water uptake, whereas fine roots are fine roots (slightly thicker than hairs), which are believed to be responsible for nutrient uptake.

${ }^{v}$ Root color was assessed on a 0 to 4 scale: $0=$ brownest and $4=$ whitest.

${ }^{{ }^{N} \mathrm{NS}}=$ not significantly different.

immediate effects on root formation (Gislerod, 1983), growth (Soffer and Burger, 1988), metabolic activity, and water and nutrient uptake (Morard et al., 2000; Sojka and Stolzy, 1988). Root respiratory oxygen demands of greenhouse crops are especially high because of their typically high rate of growth and the frequent occurrence of high temperatures inside greenhouses (Raviv et al., 2004).

Root growth-water use-gas exchangeyield relationships. As depicted on Plate 1, 
$\mathrm{T} 1, \mathrm{~T} 2$, and $\mathrm{T} 6$ had better root growth and minimal leach factor (i.e., the ratio of leached water to irrigation water), suggesting more efficient water uptake by the plants with these treatments. These plants, with greater abundance of coarse and fine roots (Table 2), probably were also more efficient in nutrient uptake, leading them to be more active in photosynthesis and transpiration. Also, these plants produced high marketable yield at a high WUE-applied (Plate 1).

\section{Conclusions}

The results of this study suggest that irrigation management should allow drying of the slabs to a certain extent before applying irrigation to accommodate oxygen, but such drying should not reach a stage where the plants would be exposed to water and salt stress. The slab-WC when used as the sole criterion in irrigation decision-making failed to control slab-EC, which is instrumental in plant water uptake as a result of its critical role in osmoregulation. This calls for the inclusion of slab-EC along with slab-WC in irrigation decision-making. A crop balance, as used in this study, demonstrated encouraging potential in monitoring the periodic water loss from the slab through evapotranspiration and hence was useful in irrigation control. We conclude that irrigation based on either slab water content $\leq 70 \%$ or $\geq 500$ g weight loss is the best strategy for rockwoolgrown greenhouse tomatoes in a long springsummer season to ensure: good root growth and (likely) function, minimized nutrient solution leaching, high photosynthesis and transpiration, high marketable yield (especially early yield), improved fruit grades, and high WUE. A variation in slab-EC between 1.4 and $1.7 \times$ normal, at a slab-WC of $\leq 70 \%$, will have no significant effect on root growth, water use, marketable yield, or fruit grades. Our results address some key current issues within the greenhouse vegetable industry.

\section{Literature Cited}

Adams, P. 1989. Some effects of root temperature on the growth and nutrient uptake of tomatoes in NFT, p. 59-71. In: Proc. 7th Intl. Congr. Soilless Culture, ISOSC, Wageningen, The Netherlands.

Allaire, S.E., J. Caron, I. Duchesne, L.-E. Parent, and J.-A. Rioux. 1996. Air-filled porosity, gas relative diffusivity and turtuosity: Indices of
Prunus $\times$ cistena sp. growth in peat substrates. J. Amer. Soc. Hort. Sci. 121:236-242.

Bar-Tal, A., M. Keinan, B. Aloni, L. Karni, Y. Oserovitz, S. Gantz, A. Hazan, M. Itach, N. Tartakovski, A. Avidan, and I. Posalski. 2001. Relationships between blossom-end rot and water availability and $\mathrm{Ca}$ fertigation in bell pepper fruit production. Acta Hort. 554:97-104.

Chrétien, S., A. Gosselin, and M. Dorais. 2000. High electrical conductivity and radiationbased water management improve fruit quality of greenhouse tomatoes grown in rockwool. HortScience 35:627-631.

Garrity, D.P., D.G. Watts, C.Y. Sullivan, and J.R. Gilley. 1982. Moisture deficits and grain sorghum performance: Evapotranspiration-yield relationships. Agron. J. 74:815-820.

Gislerod, H.R. 1983. Physical conditions of propagation media and their influence on the rooting of cuttings. III. The effect of air content and temperature in different propagation media on the rooting of cuttings. Plant Soil 75:1-14.

Hanks, R.J. 1974. Model for predicting plant yield as influenced by water use. Agron. J. 66: 660-665.

Ho, L.C. and P. Adams. 1995. Nutrient uptake and distribution in relation to crop quality. Acta Hort. 4:107-112.

Holtman, W., B. van Duijn, A. Blaakmeer, and C. Blok. 2005. Optimalization of oxygen levels in root systems as effective cultivation tool. Acta Hort. 697:57-64.

Jones, H.G. and F. Tardieu. 1998. Modelling water relations of horticultural crops: A review. Sci. Hort. 74:21-46.

Jovicich, E., D.J. Cantliffe, P.J. Stoffella, and J.J. Vansickle. 2003. Reduced fertigation of soilless greenhouse peppers improves fruit yield and quality. Acta Hort. 609:193-196.

Kläring, H.P. 2001. Strategies to control water and nutrient supplies to greenhouse crops. A review. Agronomie 21:311-321.

McAvoy, R.J. 1994. Nitrate nitrogen movement through soil profile beneath a containerized crop irrigated with two leaching fractions and two wetting agent levels. J. Amer. Soc. Hort. Sci. 119:446-451.

Morard, P., L. Lacoste, and J. Silvestre. 2000. Effect of oxygen deficiency on uptake of water and mineral nutrients by plants in soilless culture. J. Plant Nutr. 23:1063-1078.

Ontario Ministry of Agriculture and Food. 1987. Greenhouse tomato grading and packing manual. Regulation 378/90. The Farm Products Grades and Sales Act. Government of Ontario, Canada.

Papadopoulos, A.P. 1991. Growing greenhouse tomatoes in soil and soilless media. Agriculture and Agri-Food Canada Publication 1865/E.

Papadopoulos, A.P. 1998. Seasonal fertigation schedules for greenhouse tomatoes - Concepts and delivery systems. Acta Hort. 458:123-140.
Papadopoulos, A.P. and N. Liburdi. 1989. The Harrow Fertigation Manager ${ }^{\circledR}$, a computerized multifertilizer injector. Acta Hort. 260:255266.

Papadopoulos, A.P. and C.S. Tan. 1991. Irrigation of greenhouse tomatoes grown in 'Harrow' peat-bags. Can. J. Plant Sci. 71:947-949.

Raviv, M., R. Wallach, and T.J. Blom. 2004. The effect of physical properties of soilless media on plant performance-A review. Acta Hort. 644:251-259

Santamaria, P., G. Campanile, A. Parnte, and A. Elia. 2003. Subirrigation vs drip irrigation: Effect on yield and quality of soilless grown cherry tomato. J. Hort. Sci. Biotechnol. 78: 290-296.

SAS. 1999. The SAS systems for windows. Release 8.02. SAS Institute, Inc. Cary, NC.

Shelford, T.J., A.K. Lau, D.L. Ehret, and S.T. Chieng. 2004. Comparison of a new plantbased irrigation control method with lightbased irrigation control for greenhouse tomato production. Canadian Biosystem Engineering 46:1.1-1.6.

Soffer, H. and D.W. Burger. 1988. Effects of dissolved oxygen concentration in aerohydroponics on the formation and growth of adventitious roots. J. Amer. Soc. Hort. Sci. 113:218-221.

Soffer, H., D.W. Burger, and J.H. Lieth. 1991. Plant growth and development of Chrysanthemum and Ficus in aero-hydroponics: Response to low dissolved oxygen concentrations. Sci. Hort. 45:287-294.

Sojka, R.E. and L.H. Stolzy. 1988. Mineral nutrition of oxygen-stressed crops and its relationship to some physiological responses. The ecology and management of wetlands. Vol. 1. Ecology of wetlands. Croom Helm, Beckenham, UK, p. 429-440.

Sonneveld, C. 1991. Rockwool as a substrate for greenhouse crops, p. 285-312. In: Bajaj, Y.P.H. (ed.). Biotechnology in agriculture and forestry. Vol. 17. Springer-Verlag, Berlin, Heidelberg, Germany. 16 June 2006. http:// natres.psu.ac.th/Link/SoilCongress/bdd/symp19/ 2580-t.pdf.

Uronen, K.R. 1995. Leaching of nutrients and yield of tomato in peat and rockwool with open and closed system. Acta Hort. 401:443449.

Van Os, E.A. 1995. Engineering and environmental aspects of soilless growing systems. Acta Hort. 396:25-32.

Van Os, E.A. and F. Benoit. 1999. State of the art of Dutch and Belgian greenhouse horticulture and hydroponics. Acta Hort. 481:765767.

Warren, S.L. and T.E. Bilderback. 2004. Irrigation timing: Effect of plant growth, photosynthesis, water-use efficiency and substrate temperature. Acta Hort. 644:29-37. 